\title{
Poder, autoridade e liderança institucional na escola e na sala de aula: perspectivas sociológicas clássicas
}

- Carlos Alberto Gomes*

\section{Resumo}

0 presente artigo apresenta, de forma resumida, a visão sociológica de três autores clássicos - Émile Durkheim, Willard Waller e Philip Jackson - sobre a relação entre professores e alunos no quadro da relação educativa e pedagógica. Os três autores defendem uma visão hierárquica da educação e do ensino, considerando ser esse modelo institucional a melhor forma de encarar uma dinâmica interactiva inevitavelmente condicionada por um elevado potencial de conflito. Todos consideram que o sucesso da educação, em geral, e da educação escolar, em particular, depende, de modo decisivo, da eficácia da acção disciplinar, no quadro de uma liderança institucional que assegure a autoridade dos professores. É uma visão por muitos considerada tradicional e conservadora - os próprios autores tendem a considerá-la simplesmente realista - que desafia várias correntes pedagógicas antihierárquicas, e que, claramente, se opõe aos pressupostos e lógicas de acção que caracterizam o processo de personalização individualista, narcisista e hedonista da actual sociedade (pós) moderna.

Palavras-chave: Sociedade. Poder. Autoridade. Disciplina. Liderança.

\section{Power, authority and institutional leadership at school and in the classroom: classic sociological perspectives \\ Abstract}

The following article presents, in a summarized way, the sociological view of three classic authors - Émile Durkheim, Willard Waller and Philip Jackson - on the relationship between teachers and students in the context of the educational and pedagogical relationship. The three authors argue in favor of a hierarchical view of education and teaching, considering this institutional model to be the best way to envision an interactive dynamic inevitably conditioned by a considerable potential for conflict. All of them consider that the success of

* Doutor em Sociologia da Educação; Professor Auxiliar da Universidade do Minho, Portugal. E-mail: calberto@iep.uminho.pt 
education in general, and education in schools, in particular, depends decisively - on the effectiveness of disciplinary actions, in a context in which the institutional leadership gives support to the teachers' authority. It is a view considered to be traditional and conservative by many people - the authors themselves tend to consider it simply realistic- which challenges several anti hierarchical pedagogical currents, and which, clearly, is at loggerheads with presuppositions and justifications that typify the individualist, narcissistic and hedonistic process of personalization of present-day (post)modern society. Keywords: Teaching. Hierarchy. Authority. Power. Leadership.

\section{Poder, autoridad y liderazgo institucional en la escuela y en la clase: perspectivas sociológicas clásicas Resumen}

Este artículo presenta, de forma resumida, la visión sociológica de tres autores clásicos - Émile Durkheim, Willard Waller e Philip Jackson -sobre la relación entre profesores y alumnos en el ámbito de la relación educativa y pedagógica. Los tres autores defienden una visión jerárquica de la educación y de la enseñanza, y consideran que ese modelo institucional es la mejor forma de encarar una dinámica interactiva inevitablemente condicionada por un elevado potencial de conflicto. Los tres autores consideran que el éxito de la educación, en general, y de la educación escolar, en particular, depende, de modo decisivo, de la eficacia de la acción disciplinaria, en el ámbito de un liderazgo institucional que asegure la autoridad de los profesores. Es una visión considerada por muchos como tradicional y conservadora - los propios autores tienden a considerarla simplemente realista - que desafia varias corrientes pedagógicas antijerárquicas, y, que, claramente, se oponen a los presupuestos y lógicas de acción que caracterizan el proceso de personalización individualista, narcisista y hedonista de la actual sociedad (pos) moderna.

Palabras clave: Sociedad. Cultura. Socialización. Enseñanza. Reglas. Jerarquía. Poder. Autoridad. Disciplina. Liderazgo.

Neste trabalho apresentam-se sucessivamente, e de forma resumida, as perspectivas sociológicas sobre a educação e a relação pedagógica na sala de aula de três autores clássicos no campo da sociologia da educação - o sociológo francês Émile Durkheim $(1972,1984)$, um dos fundadores da sociologia moderna e da sociologia da educação, e dois autores americanos, Willard Waller (1932) e Philip W. Jackson (1975). Não obstante o seu estatuto de "autores clássicos", é muito provável que estas perspectivas sejam, ainda hoje, largamente desconhecidas. Uma característica marcante destas perspectivas reside na ligação entre a análise sociológica, a teoria 
pedagógica e a acção educativa, abordagem que se concretiza nas respectivas análises da relação pedagógica em contexto da educação escolar e da sala de aula. As análises das dinâmicas interactivas na sala de aula são claramente mais desenvolvidas nas obras de Waller (1932) e Jackson (1975), que escreveram com o assumido propósito de contribuir para a formação profissional dos professores. Deste ponto de vista terão um especial interesse abordagens da educação que, como as destes três autores, procurem deliberadamente e pragmaticamente extrair um conjunto de indicações e orientações práticas. Essas indicações surgem de forma mais evidente nas obras de Waller e de Jackson. Em Waller (1932), surgem, aliás, sob a forma de um conjunto de técnicas de liderança institucional, especificamente pensadas numa lógica de defesa da autoridade dos professores no contexto potencialmente conflitual da sala de aula. A leitura das obras 'pedagógicas' destes autores pode constituir uma surpresa para quem associe, de forma automática, a defesa de certos valores - dever, ordem, disciplina, autoridade - a uma visão conservadora da educação e do ensino. Os autores, particularmente Waller e Jackson reinvindicam para as suas análises o estatuto de "realismo sociológico": um "realismo" que os faz desconfiar e mesmo rejeitar as concepções de educação e de ensino que não se apoiem na presença clara de certas estruturas e valores - organização escolar hierárquica, distância institucional, trabalho sacrifício, dever, esforço, ordem, disciplina. Finalmente, o artigo, suscita, de forma quase inevitável, a questão de saber se estas perspectivas clássicas sobre a educação e a relação pedagógica fazem ainda hoje algum sentido - no contexto "pós-moderno de muitas das actuais sociedades democráticas, abertas e pluralistas - e se podem ter alguma utilidade (nomeadamente na formação profissional de professores) e no esforço de construção de uma escola capaz de prestar um efectivo serviço de formação cívica, democrática e humanista das jovens gerações.

\section{Émile Durkheim ${ }^{1}$}

\section{A educação como relação social assimétrica}

Para Durkheim (1984, p. 51), a educação implica inevitavelmente uma relação social assimétrica:

A educação é a acção exercida pelas gerações adultas sobre aquelas que ainda não estão maduras para a vida social. Tem por objectivo suscitar e desenvolver na criança um certo número de estados físicos, intelectuais e morais que são exigências próprias da sociedade política no seu conjunto e do meio social ao qual está particularmente destinado.

\footnotetext{
1 Émile Durkheim (1858-1917) é, com Karl Marx (1818-1883) e Max Weber (1864-1920), um dos fundadores da sociologia moderna. Durkheim é também um dos fundadores da sociologia da educação. Neste domínio são de leitura obrigatória as obras Educação e sociologia (DURKHEIM, 1972) e Educação moral (DURKHEIM, 1984).
} 
Educar as jovens gerações significa integrá-las na sociedade através da transmissão de um património cultural. 0 trabalho das gerações mais velhas, interessadas na preservação da sociedade, consiste (DURKHEIM, 1972, p. 60) em realizar a adaptação da nova geração à sociedade existente:

[...] todas as práticas educativas, quaisquer que possam ser e qualquer que seja a diferença que entre si demonstrem, apresentam um carácter comum e essencial: resultam todas da acção exercida por uma geração sobre a geração seguinte, com o fim de adaptá-la ao meio social em que esta última será chamada a viver.

De acordo com Durkheim, nas sociedades mais complexas, ou seja, nas sociedades caracterizadas por uma profunda divisão social do trabalho, esse processo de adaptação implica esforço, sacrifício e resistência por parte dos indivíduos, uma vez que as exigências de uma mais rápida integração social implicam a "queima de etapas", objectivo este que só pode ser alcançado através de um processo educativo inevitavelmente caracterizado por alguma imposição. Durkheim (1984), apoia este ponto de vista na comparação que estabelece entre as sociedades primitivas e as sociedades complexas. Nas primeiras, não existe qualquer justificação lógica para a coerção na acção educativa:

Que a educação seja necessariamente mais austera entre o ser civilizado do que entre o ser primitivo, é o que podemos facilmente explicar. A vida do ser primitivo é simples; os seus pensamentos são pouco numerosos e complexos; as suas ocupações pouco diversificadas repetem-se continuamente. Por consequência, é natural que a educação que prepara a criança para a vida que ela há-de um dia levar, se revista da mesma simplicidade. Podemos mesmo afirmar que nessas espécies de sociedade a educação é quase inexistente. A criança aprende facilmente tudo aquilo que necessita de aprender por experiência directa e pessoal; é a vida que a instrui, sem que seus pais tenham que intervir. $\dot{E}_{\text {, portanto, o }}$ princípio do 'deixar correr' que predomina e, por consequência, a severidade sistemática, organizada, não tem razão de ser (DURKHEIM, 1984, p. 293-294).

Ao contrário, nas sociedades complexas, a educação só é possivel no quadro de um determinado e inevitável nivel de imposição e coerção:

A verdadeira educação só se inicia quando a cultura mental e moral, adquirida pela humanidade, se tornou demasiado complexa, e desempenha um papel excessivamente importante no conjunto da vida comum, para que possamos deixar ao acaso o cuidado de assegurar a sua transmissão 
de uma geração para a geração seguinte. Então, os mais velhos sentem a necessidade de intervir, de efectuarem eles próprios essa transmissão indispensável, sumariamente, fazendo com que as ideias, os sentimentos e os conhecimentos transitem directamente da sua consciência para a consciência dos jovens. Em vez de permitirmos que estes se instruam por si próprios, espontaneamente, instruímo-los nós. Ora uma acção deste género tem necessariamente algo de coercivo e laborioso, já que constrange a criança a ultrapassar a sua natureza de criança, a violentá-la, porquanto procura obrigá-la a amadurecer mais rapidamente do que essa mesma natureza permite; porquanto, doravante, em vez de deixar a sua actividade divagar livremente, ao sabor das circunstâncias, necessário se torna que a criança se concentre, voluntariamente, penosamente, nos temas que lhe são impostos (DURKHEIM, 1984, p. 294).

\section{A imposição de regras e a autoridade moral do professor}

A educação escolar não é possível sem a definição e a imposição de um conjunto de regras que devem ser respeitadas. É preciso que os alunos adquiram certos valores, certas crenças, certos hábitos, certas atitudes. Cumprindo um mandato social, o professor deve actuar no sentido de os levar a respeitar certas regras. Na prática, este objectivo pressupõe e exige que o professor tenha autoridade (DURKHEIM, 1972, p. 53-54):

[...] a educação deve ser um trabalho de autoridade. [...] Para aprender a conter o egoísmo natural, subordiná-lo a fins mais altos, submeter os desejos ao império da vontade, conformá-los em justos limites, será preciso que o educando exerça sobre si mesmo um grande trabalho de contenção. Ora, não nos constrangemos não nos submetemos senão por uma destas razões: ou por força da necessidade física, ou porque o devamos moralmente. Mas a criança não pode perceber a necessidade que nos impõe fisicamente tais esforços, porque ela não se acha em contacto imediato com as duras realidades da vida [...]. Fica o dever. 0 sentimento do dever. É ele o estimulante capital do esforço para a criança e mesmo para o adulto. [...] Mas a criança não pode conhecer o dever senão por seus pais e mestres; Não pode saber o que ele seja senão graças ao modo pelo qual mestres e pais o revelarem, na conduta e linguagem. preciso, portanto, que eles sejam para o educando o dever personificado. Isso significa que a autoridade moral é a qualidade essencial do educador. 
Como se pode concluir, para Durkheim (1972), a autoridade do professor deve ser sobretudo definida em termos morais. Não se trata tanto de um conjunto de prerrogativas regulamentares ou de uma definição administrativa ou burocrática dos direitos e funções dos professores. Pelo contrário, a autoridade pressupõe a adesão do professor a um conjunto de valores e de códigos de conduta que devem ser transpostos para a relação educativa sob a forma de exemplos, de referência morais, que venham a ser interiorizadas pelos alunos:

A autoridade é uma força que ninguém pode manifestar, se efectivamente a não possui. Donde pode vir ela? Será do poder material de que se arma? Do direito de punir e de recompensar? Mas o temor do castigo é coisa diversa do respeito à autoridade. Esse temor não tem valor moral senão quando o castigo seja reconhecido como justo por aquele que o recebe e isso implica que a autoridade, ao punir, já é reconhecida como legítima. E a questão é precisamente essa. Não é de fora que o mestre recebe a autoridade: é de si mesmo. Ela não pode provir senão de fé interior. [...] 0 que faz a autoridade de que tão facilmente se reveste a palavra do sacerdote, é a alta ideia que tem da sua missão porque ele fala em nome de uma divindade na qual tem fé de quem se sente mais próximo do que a multidão dos profanos. 0 mestre leigo pode e deve ter alguma coisa desse sentido. Ele também é o órgão de uma grande entidade moral: a sociedade. (DURKHEIM, 1972, p. 55-56).

\section{Controlo disciplinar e recusa do autoritarismo}

Sem autoridade, o professor não está, pois, em condições de levar a cabo a sua missão educativa. Sem autoridade não é possível levar os alunos a respeitar certas regras morais. Respeito, significa, muito precisamente, na perspectiva pedagógica de Durkheim (1972), o convencimento do carácter benéfico da regra. 0 respeito pela regra pressupõe o respeito pelo professor. Todavia, o aluno só pode respeitar o professor, se este, por sua vez, adoptar uma conduta que favoreça esse objectivo. 0 professor só ganhará o respeito dos alunos se fizer educação e não domesticação, se souber estabelecer, claramente, a diferença entre autoridade e autoritarismo, e se, em consequência desta distinção, adoptar uma linha de conduta intencionalmente educativa, que conduza os alunos a compreender a utilidade do respeito por certos princípios morais. Ora, na escola, nem todas as linhas de conduta adoptadas pelo professor com o objectivo de garantir a conformidade em relação às regras morais, são susceptíveis de engendrar o respeito pela autoridade. Muito pelo contrário, determinadas formas de controlo disciplinar podem conduzir a situações em que o professor perde a sua autoridade perante os alunos, comprometendo, desse modo, a eficácia da acção educativa. É o que se passa com as formas autoritárias de controlo do comportamento dos alunos na sala de aula. Durkheim (1984, p. 262-263), é muito claro a este respeito: 
[...] sempre que falamos da autoridade do mestre, da sua necessidade, não queremos de forma alguma dizer que ele deva orientar uma classe como um regimento. Certamente nada é mais oposto ao espírito da disciplina, do que dissimulá-la sob aparências agradáveis. [...] Nem tudo na vida é um divertimento; é portanto necessário que a criança se prepare para o esforço, para o sofrimento e, por consequência, seria desastroso fazer-lhe crer que se pode fazer tudo a rir. Mas, em primeiro lugar, a vida social não é uma vida de campanha; e, por outro lado, uma vez que a criança deve ser iniciada na vida a sério, há que não esquecermos nunca de que se trata tão somente de uma iniciação, de uma primeira introdução, de que a criança não é um homem e deve ser tratada de conformidade com a sua natureza de criança. A autoridade do mestre, deve portanto temperarse com benevolência, de forma a que a firmeza não degenere em rudeza e inflexibilidade.

Este conceito de autoridade é essencial na concepção pedagógica e educacional de Durkheim. Assim definida, a autoridade implica o respeito pela dignidade e pela individualidade dos alunos. E implica também, e de forma decisiva, uma aceitação consciente de valores morais. Em consequência, o respeito pela autoridade não pode ser conseguido através da utilização de métodos puramente coercivos. Transpondo esta concepção para a escola, Durkheim rejeita o autoritarismo e a militarização da sala de aula, pois, nessa situação, os alunos obedecem na base do medo e não porque estejam convencidos da vantagem para a vida que decorre da observação e respeito por certas regras. A recusa do autoritarismo, da militarização da vida na sala aula, não significa, contudo, que o professor deva basear toda a sua conduta na base da persuasão, ou do apelo constante e repetido. De facto, a questão prática que se coloca é a de saber como agir, nos casos em que a persuasão não funcione. Sem outros meios de acção, o professor perderia, inevitavelmente, a sua autoridade. E, sem ela, não é possivel levar a cabo a missão social da escola. Ora, como acima vimos, educação implica, para Durkheim, algum grau de coacção, ou seja, de constrangimento. E é assim porque, de outro modo, a escola e os professores não conseguiriam criar os hábitos, as condutas, em suma, as disposições indispensáveis a uma resposta positiva às exigências da vida escolar. Está implícito, na análise de Durkheim, a possibilidade de os alunos, ou, pelo menos, alguns deles, não aceitarem, de bom grado, o conjunto de sacrificios e de esforços que the são pedidos. 0 que é o mesmo que dizer que não está garantida, de forma automática, a sua adesão ao projecto da escola e do professor. Como observa Durkheim (1984, p. 266): "[...] existem pouquíssimas crianças predispostas a revoltarem-se abertamente contra o mestre, a afrontá-lo de frente, a ofender os seus companheiros [...]. No entanto, inúmeras são aquelas que são propensas a não se aplicarem, a distraírem-se, etc [...]". 
Ora, como explica Durkheim (1984, p. 276), se os professores não dispusessem de meios legítimos para obrigar os alunos a respeitar as regras da escola e a cumprirem as obrigações que elas necessariamente implicam, o projecto social da escola ficaria em causa:

Com efeito, a maior parte das obrigações a que o aluno se encontra sujeito, não têm a sua finalidade em si mesmas, nem sequer num futuro muito próximo, já que são simples exercícios destinados a preparar a criança, tendo em vista a vida que ela irá levar quando adulta. Se lhe pedimos que se aplique, que não se deixe dominar pela preguiça, pela sua distracção naturais, não é somente para que ela execute convenientemente os seus deveres, que são a glória do mestre e da classe; é sim para que ela adquira a cultura que irá utilizar mais tarde, o hábito do esforço de que um trabalhador carece para conseguir um lugar na sociedade. Portanto, é somente quando tiver saído da escola, quando estiver empenhada na vida a sério, que decorrerão as consequências naturais do comportamento que tiver tido enquanto estudante. Será preciso dizer que, se a criança aguardar até então, para se dar conta dos seus actos, será tarde demais?

\section{A disciplina e a punição educativa}

Para Durkheim (1984), em caso algum a escola deve admitir a possibilidade de se demitir da finalidade social que justifica a sua criação, ou seja, educar as jovens gerações. Nessa perspectiva, os alunos devem ser, não apenas persuadidos, mas também, se necessário, obrigados a respeitar certas regras, a não fugirem a certas obrigações. Mas como é que a escola, e os professores, podem obrigar os alunos a respeitarem certas regras de conduta e a cumprirem as suas obrigações escolares? A resposta de Durkheim (1984, p. 285), é inequivoca: a escola deve punir as condutas que se desviem das regras instituidas, pois "é devido ao facto da criança ter a obrigação de trabalhar, que a preguiça, a negligência são faltas morais que devem ser punidas". Mas a punição só tem utilidade educativa se for aplicada de forma a que os alunos compreendam claramente a razão da sua aplicação e interiorizem a necessidade de, para benefício próprio, ajustarem o seu comportamento àquilo que a norma prescreve. A punição não visa a mera modificação superficial dos comportamentos. Isso pode ser conseguido através da coacção, mais ou menos violenta. Mas, nesse caso, 0 aluno pode ser vencido, mas não fica convencido. Exemplificando, diriamos que um aluno que é sancionado por se distrair na sala de aula, na base de uma mera acção coercitiva, passará, para se proteger, a adoptar comportamentos congruentes, por exemplo fingindo atenção, mas não ficará convencido das razões que levam a considerar a distracção na sala de aula como um comportamento prejudicial para o seu desenvolvimento moral e cognitivo. Este é um argumento fundamental na pedagogia defendida 
por Durkheim. É muito importante realçá-lo, porque são frequentes as confusões entre autoridade e autoritarismo, confusões que conduzem, frequentemente, a ideias erradas acerca do papel da punição na escola. Para Durkheim (1984), a punição é um instrumento essencial da educação escolar. Ela é, em si própria, educação. De facto, sem ela, é praticamente impossivel levar os alunos a entender as razões que estão na base da valorização positiva ou negativa de certos comportamentos. Para Durkheim, a punição é algo de necessário, algo de indispensável na escola. Sem ela o professor estaria destituído de meios efectivos de controlo e pressão sobre os alunos. É a punição que, como explica Durkheim (1984, p. 279-280): "[...] impede que a regra perca a sua autoridade, autoridade essa que as infracções cometidas diariamente lhe retirariam progressivamente, se acaso se mantivessem impunes. Isto porque, aquilo que faz a sua autoridade é o facto da criança a considerar inviolável".

Mas tão importante como punir a falta de respeito pelas regras morais, é saber como punir, como censurar, é, em suma, saber como produzir, através do acto da punição, um acto essencialmente educativo, um acto que leve o aluno a transformar voluntária e conscientemente o seu comportamento. Como escreve Durkheim (1984, p. 307), "a forma de castigar tem tanta importância quanto a própria punição". Nesta perspectiva, existem duas formas de castigo a evitar:

O castigo aplicado com base na cólera (DURKHEIM, 1984, p. 307):

Com efeito, é necessário que a criança não julgue ter sido castigada num impulso de cólera irreflectida, de impaciência nervosa. Isso seria suficiente para desacreditar a pena a seus olhos, e para lhe retirar todo o significado moral. É necessário que a criança sinta que o castigo foi deliberado, e que resulta de uma decisão tomada a sangue-frio.

E o castigo aplicado de uma forma fria (DURKHEIM, 1984, p. 308):

[...] se é certo que não devemos castigar, levados pela cólera, não é menos certo que não devemos castigar friamente. Um excesso de sangue frio, de impassibilidade, não resulta meIhor do que um excesso de arrebatamento. Com efeito, punir, dissemos nós, é reprovar, e reprovar é protestar, é repelir o acto que reprovamos, é darmos provas do distanciamento que ele inspira. Logo, se a punição for aquilo que deve ser, ela não se processa sem uma certa indignação, ou, se a expressão parecer demasiado forte, sem um descontentamento mais ou menos denunciado. Desde que lhe retiremos a afeição, o castigo esvaziar-se-á de todo o seu conteúdo moral. [...] Tudo se passa automaticamente. Estabelece-se uma tarifa: a criança sabe que, por cada falta, terá de pagar; ela paga 
passivamente, devido à injunção recebida; mas, uma vez paga a sua conta, ela considera-se desobrigada para consigo própria e para com os outros, porquanto, na punição, ela não mais vê do que a própria punição. Assim entendida, a disciplina pode perfeitamente adestrar, mas não educar, uma vez que não produz um trabalho interior.

É nesta passagem que, com mais clareza, se pode entender a lógica que comanda as concepções educacionais e pedagógicas de Durkheim. A escola e, nela, a sala de aula, é um lugar de educação, de socialização, não de domesticação ou de adestramento. As regras só têm eficácia educativa se forem aplicadas de modo a impulsionarem um trabalho interior, ou seja, o ajustamento do comportamento às regras, não por receio ou medo, mas por convencimento da sua razão de ser, da sua utilidade para aquele que a ela se conforma, activa e conscientemente. Fica também melhor esclarecida a aversão de Durkheim às concepções autoritárias da educação. É que tais concepções destinam-se a produzir resultados na base da pura coerção: não pressupõem, nem exigem, qualquer tipo de adesão voluntária.

Em síntese, destacamos, como tópicos centrais de interesse para o debate actual sobre a educação e a educação escolar em particular, a ênfase dada por Durkheim ao papel da autoridade na educação e a sua distinção entre os conceitos de autoridade e de autoritarismo.

\section{Willard Waller ${ }^{2}$}

\section{Educação, ensino e realismo sociológico}

Em The Sociology of Teaching (WALLER, 1932), opondo-se a uma visão idealizada do ensino, Waller propõe-se oferecer uma visão da escola tal como ela é$^{3}$, ou seja, propõe-se descrever e analisar o que, na sua perspectiva, efectivamente se passa na escola, e, particularmente, na sala de aula. Para Waller, só este realismo sociológico pode ajudar os professores (e, principalmente, os professores em princípio de carreira), a compreenderem as bases profundas dos problemas concretos com que se deparam na relação social que mantêm com os alunos, e, principalmente, a entenderem a dinâmica conflitual da relação pedagógica.

Eu acredito que todos os professores [...], têm necessidade de uma perspectiva sobre as realidades sociais da escola, que eles podem perder-se como professores, pela falta dessa perspectiva. Jovens professores falham por-

2 Willard Waller (1899-1945), sociólogo e professor, escreveu uma das mais profundas e interessantes obras sobre a interacção na sala de aula no contexto da escola como organização. É absolutamente impressionante ver como o seu The Sociology of Teaching, publicado em 1932, mantém uma fortissima actualidade nos dias de hoje.

3 Como escreveu Waller (1932, prefácio): "Se quero ajudar outros a obter uma perspectiva útil, eu devo mostrar-lhes a escola tal como ela realmente é. Eu não devo atacar a escola, nem falar demasiado acerca do que ela devia ser, mas apenas acerca do que ela é". 
que não sabem como manter a ordem. Especialistas briIhantes fazem o seu trabalho deficientemente porque não entendem a natureza humana da sala de aula. A formação de professores tem feito muito para promover o desenvolvimento geral da instrução, mas tem de fazer muito mais para equipar os professores principiantes com essa perspectiva. (WALLER, 1932, prefácio).

É muito importante que independentemente da experiência profissional obtida, os professores apoiem a sua prática num conhecimento teórico, o mais aprofundado possivel, acerca das realidades sociais da escola. Não obstante reconhecer o valor e a utilidade do conhecimento prático obtido através da experiência, Waller (1932, p. 1), realça as limitações desse conhecimento:

\begin{abstract}
Não é para desacreditar a formação de professores que nós insistimos no facto de que os professores continuam a aprender a ensinar ensinando. 0 professor obtém algo da experiência que não está incluído nos seus cursos 'profissionais', uma coisa indefinivel que é difícil encontrar entre as páginas de um livro ou no ensino. Essa coisa indefinivel é a perspectiva social. Aquilo que o professor obtém da experiência é uma compreensão da situação social na sala de aula, e uma adaptação da sua personalidade às necessidades do meio. [...] As crianças e os professores não são [...] máquinas de ensinar nem máquinas de aprender, mas seres humanos completos ligados num complexo labirinto de interconexões sociais.
\end{abstract}

\title{
As características estruturais da escola
}

Educar e ensinar na escola exige que, em certa medida, os professores se transformem em "sociólogos práticos", pois sem essa sensibilidade ao social tudo se torna mais complexo e difícil. Assim, de acordo com Waller (1932, p. 6-7), o exercício da actividade profissional e muito particularmente a relação com os alunos na sala de aula implica ter em consideração:

Que a escola é um sistema fechado de interacção social:

A escola existe sempre e quando professores e alunos se encontrem para o objectivo de dar e receber instrução. A instrução que é dada é usualmente instrução formal na sala de aula [...]. 0 dar e receber instrução constitui o núcleo da escola [...]. Quando estudamos as escolas existentes, vemos que elas têm as seguintes características que nos permitem considerá-las à parte e estudá-las como entidades sociais: (1) têm uma população definida; (2) têm uma estrutura política claramente defi- 
nida, que surge do modo de interacção social, e influenciada por numerosos processos de interacção; (3) esses processos de interacção representam a conexão de uma rede compacta de relações sociais; (4) elas são impregnadas por um sentimento de grupo; (5) elas têm uma cultura própria.

Na qual, o modo de interacção social determina (WALLER, 1932, p. 8), uma ordem política que confere aos professores uma posição de domínio:

0 característico modo de interacção da escola, uma interacção baseada em volta do dar e receber instrução, determina a ordem política da escola. A instrução que é dada consiste principalmente em factos e aptidões, e por outras matérias para as quais os interesses espontâneos dos alunos não fornecem usualmente uma motivação suficiente. [...] Face à comunidade, os professores são responsáveis pela aprendizagem dos alunos. Por conseguinte, a organização política da escola atribui o domínio ao professor, é da responsabilidade do professor usar o seu domínio e perceber que ele é central na interacção social da escola.

No quadro de uma lógica de dominação autocrática (WALLER, 1932, p. 8-9): "Normalmente, a escola está organizada numa qualquer variante do princípio autocrático. [...] A generalização de que as escolas têm uma estrutura política despótica parecer ser verdade praticamente para todos os tipos de escolas [...].

Que, contudo, é permanentemente ameaçada, pois:

Não é suficiente salientar que a escola é um despotismo. É um despotismo num estado de equilibrio precário. É um despotismo ameaçado de dentro e exposto à regulação e à interferência de fora. É um despotismo capaz de ser destruído num momento, exposto a uma perda momentânea da sua estabilidade e do seu prestígio. [...] É um despotismo exercido sobre os alunos (que são) o mais manejável e o mais instável membro da comunidade. [...] Para entender a estrutura política da escola temos de saber que a escola está organizada no princípio da autoridade e que essa autoridade está constantemente ameaçada (WALLER, 1932, p.10).

Em primeiro lugar, pelas suas divisões sociais internas:

A relação social centrada na escola pode ser analisada em termos de grupos de interacção na escola. Os dois grupos mais importantes são o grupo dos professores e o grupo dos alunos, cada um tendo a sua própria moral e o seu 
código ético e as suas habituais atitudes em relação aos membros de outros grupos. Existe uma acentuada tendência para esses grupos se transformarem em grupos de conflito. Dentro do grupo de professores existem divisões relativas ao status e posição, grupos hostis e conspirativos, [...] e cliques organizadas em torno de diferentes personalidades. Dentro do grupo de alunos existem várias divisões representando grupos na comunidade mais larga, grupos primários não organizados organizados segundo idades, cliques, organizações políticas e grupos especializados como equipas e gangs (WALLER, 1932, p.12).

E, em segundo lugar, pelos alunos, que agem no sentido da satisfação de interesses e objectivos próprios.

Os professores e os alunos confrontam-se com atitudes das quais a subjacente hostilidade que nunca poderá ser completamente eliminada. Os alunos são o material com que é suposto os professores produzirem resultados. Os alunos são seres humanos lutando para se realizarem de uma maneira espontânea, lutando para alcançar os seus próprios objectivos, à sua própria maneira. Cada uma destas partes hostis coloca-se no caminho da outra; na medida em que os objectivos de uma sejam realizados, isso é feito com sacrifício dos objectivos da outra (WALLER, 1932, p.196).

\section{Instrução de massas, imposição e ordem na sala de aula}

Waller procura desvendar as origens últimas da conflitualidade na relação educativa. Este passo na análise é, como veremos, muito importante para entender a sua ênfase na indispensabilidade da utilização de um modelo de liderança institucional, de tipo hierárquico. Assumindo uma perspectiva próxima da de Durkheim, Waller (1932, p. 104), sublinha a ideia de que a escola é uma instituição social vocacionada para a educação das jovens gerações, devendo realizar esse trabalho através da tentativa de inculcação de valores e atitudes e do ensino de certas aptidões. 0 professor, representante da geração adulta, deve educar e ensinar. Ao fazê-lo procura fazer aceitar certos valores e ideais, tidos como válidos pela geração de que faz parte. 0 aluno é o destinatário dessa acção. É o objecto da acção educativa, quer ela se faça sentir no plano moral ou no plano cognitivo:

\section{[...] a escola está envolvida na transmissão de um vasto conjunto de cultura que é transmitida dos velhos para os novos. A escola deve ensinar aptidões e deve implantar atitudes. Em qualquer altura e em qualquer comunidade a maior proporção do trabalho da escola é o de impor aos alunos os pré-existentes padrões da comunidade.}


Para além de valores, a escola tem que transmitir conhecimentos (WALLER, 1932, p. 355):

É apenas porque os professores desejam obrigar os alunos a estudar que algum desprazer aparece sempre a frustar a sua relação. Definimos a escola como um lugar onde as pessoas se encontram para o objectivo de dar e receber instrução. Se este processo não fosse forçado, se fosse permitido aos alunos só aprenderem aquilo em que estivessem interessados, aprendendo à sua maneira, e aprenderem não mais do que aquilo que gostassem, se a ordem não fosse considerada uma condição necessária para a aprendizagem, se os professores não tivessem que obrigar os alunos a realizar tarefas, mas sendo apenas ajudantes e amigos então a vida na sala de aula seria doce. Estas, contudo, são todas condições contrárias aos factos. As condições de instrução de massas [...] tornam necessário que o ensino seja forçado. Os alunos devem aprender muitas coisas que eles não desejam aprender, e devem aprender até à náusea mesmo as coisas que lhe interessam. Os professores têm que obrigar os alunos a trabalhar. Os professores devem manter a ordem na sala de aula de modo a que os alunos possam aprender.

Estas funções da escola dão origem a conflitos sociais e culturais. Em particular, entre os professores e os alunos, surge, segundo Waller (1932, p. 104), um conflito provocado pelo facto de "os professores serem adultos e os alunos não e deste modo os professores são os defensores da cultura da sociedade dos adultos, e tentam impôr essa cultura aos alunos [...]". De acordo com Waller (1932, p.195-196), devido a razões de ordem cultural, não existe uma identidade de perspectivas entre os professores e os alunos, facto que está na base de um inevitável conflito de interesses:

Na escola, o professor e o aluno confrontam-se num original conflito de interesses, e por mais que esse conflito seja desvalorizado, ou por mais que seja escondido, ele permanece. 0 professor representa a geração adulta, eternamente o inimigo da vida espontânea dos grupos de crianças. 0 professor representa o currículo formal, e o seu interesse é impôr esse currículo aos alunos sob a forma de tarefas; os alunos estão muito mais interessados em viver no seu mundo próprio do que no áridos momentos da vida adulta que os professores oferecem. 0 professor representa a ordem social estabelecida na escola e é do seu interesse manter essa ordem, ao passo que os alunos têm apenas um interesse negativo nessa superestrutura feudal.

Para entender a lógica subjacente a este conflito é preciso investigar as razões da resistência dos alunos à acção educativa da escola (incluindo, no conceito de 
aç̧ão educativa, a transmissão de valores e conhecimentos, ou seja, a acção da escola no plano moral e no plano cognitivo). Para Waller (1932, p. 59), o principal factor a destacar é o facto de a dinâmica própria dos alunos ser deliberadamente orientada para a rejeição de tudo o que, de algum modo, possa pôr em causa, a sua "vida espontânea", ou o seu "mundo próprio". 0 professor, assevera (WALLER, 1932, p. 59), "[...] deve viver num universo de valores e atitudes adolescentes" e, no interior desse universo, deve impor um currículo formal, orientando os alunos para objectivos que só podem ser alcançados com esforço e sacrifício de interesses pessoais ou de grupo. Nesta perspectiva, a escola, enquanto instituição social, deve definir-se como um lugar decididamente orientado para uma lógica (e uma prática) de trabalho e não de diversão.

\section{A liderança institucional}

Perante as dinâmicas próprias dos alunos, e perante a inevitabilidade do conflito na acção educativa, a escola deve apoiar-se num modelo de liderança que impeça, ou, pelo menos, torne altamente improvável, uma completa subversão da autoridade dos professores. Esse modelo de liderança é o da liderança institucional. Apoiando-se nesse modelo, os professores estarão melhor preparados para enfrentarem a situação social típica da escola que é a da conflitualidade congénita inerente ao carácter necessariamente impositivo da acção educativa. A consideração das caracteristicas do modelo de liderança institucional deve ser feita, recorda Waller (1932, p. 173), tendo sempre presente o problema essencial a que ela visa responder, ou seja, o potencial de subversão dos alunos, que se expressa em diversas formas, activas e passivas, de resistência à acção educativa:

Em si própria a desordem é epidémica na escola. Os
professores sabem que certos comportamentos tendem
a estender-se a toda a escola, passando de uma sala de
aula para outra [...]. Tal comportamento é o de lançar
moedas, lançar bombas de mau-cheiro, etc. Quando a
escola está localizada num edifício em ruínas é possível
aos alunos fazê-lo vibrar por pequenos e quase inde-
tectáveis movimentos se esses movimentos forem ade-
quadamente sincronizados; quando comportamentos
deste tipo são iniciados é muito difícil pará-los. Vários
tipos de risos, a maior parte deles artificiais e com aque-
la rouquenha qualidade que conota a violência ou o
desrespeito podem tornar-se epidémicos.

É para tentar evitar situações como esta que Waller defende ser importante que a escola se apoie num modelo de liderança capaz de proteger a relação institucional de superordenação-subordinação. Nessa perspectiva (WALLER, 1932, p. 189), estabelece a distinção entre dois tipos de liderança: 


\section{A liderança pessoal:}

Algumas pessoas lideram porque não o podem evitar. Elas lideram espontaneamente, e talvez sem a consciência do facto de que estão liderando. [...] Tal liderança surge inevitavelmente da associação de pessoas diferentes: tem as suas origens na complexidade mental relativa do líder que o torna imprevisivel para aqueles que ele lidera. 0 líder tem de ser um pouco mais rápido a agir do que os seus seguidores, um pouco mais determinado nas suas decisões, um pouco mais determinado em levar avante os seus projectos; o liderado tem que ter alguma fé na competência do líder. Estas são as condições básicas da liderança pessoal.

E a liderança institucional: "Outras pessoas lideram porque têm de liderar. É estabelecida uma situação social e são determinados os seus padrões. 0 padrão é tal que exige um líder. 0 padrão também determina o que o líder deve fazer com os liderados. Esta é a liderança institucional" (WALLER, 1932, p. 189).

Waller reafirma, enfaticamente, a necessidade de a escola se apoiar num modelo de liderança institucional. Com efeito, dentro desse modelo, os professores devem agir exclusivamente no âmbito dos padrões e das expectativas sociais e institucionais prescritas ou previstas. E o mesmo é válido para os alunos, pois, uma vez adoptado, o modelo de liderança institucional estabelece padrões de conduta obrigatórios para todas as posições institucionais nele incluídas. Em consequência, professores e alunos devem agir dentro das normas pré-estabelecidas que estabelecem limites formais. Não inventam nada. Limitam-se a desempenhar papéis pré-estabelecidos. Ao professor está destinado um papel de domínio. Ao aluno, um papel de subordinação. Em princípio, ou seja, num plano meramente teórico ou formal, o professor está, neste quadro institucional, numa posição segura. E isto porque, como sublinha Waller (1932, p. 190),

A liderança institucionalizada ganha por uma rígida demarcação de fronteiras e pela rígida aderência a elas. A influência pessoal tem de ser sempre forçada através do filtro da formalidade. A liderança institucional não pode permanecer institucional a não ser por uma insistência sobre as linhas de demarcação, porque há sempre uma tendência para, nessa situação, a interacção humana transcender essas linhas de fronteira.

É na "insistência sobre as linhas de demarcação" que se deve centrar a liderança institucional do professor, de forma a poder sair vencedor no contexto potencialmente conflitual da sala de aula. Para garantir o respeito por essa demarcação, os professores podem utilizar vários meios que serão tanto mais eficazes quanto mais ligados estiverem às características intrínsecas da liderança institucional: demarcação de fronteiras entre superiores e subordinados, rígida adesão às regras e regulamentos, formalidade 
das relações. Este último aspecto - a formalidade da relação entre o superior e o subordinado - é considerado essencial. Com efeito, sublinha Waller (1932, p. 195):

A formalidade é um compromisso, um ajustamento, que permite que a liderança institucional sobreviva. As formalidades, um complicado ritual social e um corpo de regras e regulamentos, definem, de uma vez por todas, os direitos e os privilégios de todas as pessoas envolvidas na situação. $A$ formalidade previne a fricção evitando o contacto de personalidades. [...] A formalidade relaciona-se normalmente, a um nivel superficial, com as fórmulas de respeito e consideração devidas pelo inferior ao superior. [...] Mas a formalidade não é unilateral, pois ela confere um igual benefício ao subordinado. Ela permite-lhe, se se conformar com todas as normas externas, reduzir a pressão psíquica dessas fórmulas de respeito a nada, se ele quiser, mecanizar o ritual do respeito à sua vontade e viver uma vida interior noutro nível. Nós saudamos o uniforme e não o homem. E a formalidade protege o inferior das exigências arbitrárias do superior.

A liderança institucional não é, portanto, uma panaceia, uma varinha mágica. Não basta adoptá-la, em sentido formal, para que, ipso facto, se obtenham os efeitos desejados. A sua sobrevivência e eficácia dependem, muito directamente, da capacidade de a pôr em prática no respeito pelas suas características próprias. Como se destina a ser aplicada por pessoas e não por máquinas, a liderança institucional pode ser ameaçada por uma defeituosa aplicação, ou, para se ser mais rigoroso, por desvios em relação às suas específicas condições de eficácia. Em segundo lugar, a liderança institucional traduz uma situação de desequilibrio de poder. Os indivíduos que nesta forma de interacção social ocupam posições de domínio, impõem a sua vontade aos que ocupam uma posição subordinada. A imposição da vontade de uns implica, sempre, a anulação da vontade, dos interesses e dos objectivos de outros. Todavia, é preciso ter em consideração que, em última análise, os subordinados não estão totalmente despojados de capacidade de resistência às imposições institucionais, ou seja, dispõem sempre de uma determinada capacidade de mobilizar o seu poder ou a sua força contra a autoridade, que, por definição, é monopolizada por aqueles que ocupam os lugares de decisão na hierarquia institucional. Admitir esta possibilidade é, desde logo, reconhecer que, em circunstâncias especiais, a liderança institucional pode ser posta em causa. Na escola, afirma Waller (1932, p. 196), são as dinâmicas próprias dos alunos, que em múltiplas circunstâncias, podem fragilizar, ou mesmo anular, a posição de liderança institucional dos professores:

Quaisquer que sejam as regras impostas pelo professor, a tendência dos alunos é a de as esvaziarem de sentido. Pela mecanização da conformidade, pela ridicularização do professor ou pela hostilização do professor enquanto pessoa, procu- 
rando refúgio em iniciativas próprias que estão sempre para além do controlo do professor, os alunos tentam neutralizar o controlo do professor. 0 professor contudo luta para dar sentido às regras e regulamentos, para fazer dos padrões verdadeiros padrões, para obrigar os alunos a conformarem-se. [...] 0 poder do professor para definir regras não é limitado, mas é o seu poder para impôr as regras e também o seu poder de controlar as atitudes em relação às regras.

Por si só, a relação institucional-formal de domínio-subordinação não assegura o previsto desempenho de papéis. Por um lado, os professores apesar de beneficiarem de uma posição de superioridade hierárquica, na prática nem sempre actuam de forma a garantir a eficácia dessa posição, e, por outro lado, os alunos, não obstante se encontrarem numa posição de subordinação institucional, nem sempre actuam de acordo com as expectativas ligadas a essa posição, fazendo com que os professores corram o risco de perderem o controlo das situações. Para Waller (1932), a prevenção desta possibilidade exige uma adequada aplicação do modelo de liderança institucional, pois só assim se torna possivel manter sob controlo eficaz a dinâmica tendencialmente subversiva dos alunos. Com efeito, a liderança institucional, quando eficazmente aplicada, reduz, ou no melhor dos casos, elimina, as possibilidades de subversão ou desvio por parte dos alunos. E isto porque este tipo de liderança, assente na demarcação de fronteiras, na formalidade, e no estabelecimento de sanções pré-estabelecidas, elimina os factores de ambiguidade na relação superior-subordinado, dificultando a manipulação do líder, numa base pessoal ou emocional. É por todas estas razões que Waller (1932, p. 192), conclui que "a escola depende quase inteiramente da liderança institucional". Mas, como veremos em seguida, o que Waller pretende de facto dizer com esta declaração é que a escola depende, do ponto de vista da realização do mandato social de que foi incumbida (socialização e instrução das jovens gerações), da capacidade demonstrada pelos professores na aplicação do modelo de liderança institucional. Declarando que a defesa que faz deste modelo de liderança se deve sobretudo a razões pragmáticas, enquadradas num intencional realismo sociológico, Waller (1932, p. 192-193), mostra-se preocupado com a falta de preparação principalmente dos jovens professores, para lidar com as duras realidades da escola:

Nós não somos adeptos do tipo de liderança institucional que está hoje em voga nas escolas. Entre a limitada e apertada interacção pessoal que tem hoje lugar nas escolas e o mais livre companheirismo advogado pelos escritores progressistas, a nossa preferência vai para o último tipo de situação. Mas nós sentimos que quer a teoria quer a prática da educação sofreram no passado de uma excessiva atenção em relação ao que deve ser e a sua correlativa tendência para negligenciar aquilo que ela é. Quando a teoria não se apoia na prática existente, aparece um grande hiato entre a teoria e a prática, e a consequência é a 
de que o progressivismo da teoria não afecta o conservadorismo das práticas. 0 aprendiz de professor aprende a mais avançada teoria da educação e vai para a escola com a firme determinação de a pôr em prática. Mas ele descobre que essa teoria dáIhe pouca ajuda para lidar com as situações concretas com que se confronta. Depois de algumas tentativas para transpôr as teorias para a prática educacional, ele desiste e procura guiar-se pelas bases convencionais, pelo conselho dos professores mais velhos, pelos provérbios da fraternidade e pelas ordens dos directores. É este fracasso da ciência da educação para lidar com as realidades, que é o principal responsável pelo lento ritmo do progresso na prática educativa.

\section{As técnicas de liderança institucional}

Procurando contribuir para a superação deste problema Waller (1932, p. 198203), oferece uma análise da "técnica de liderança institucional"4 der, ao falar de técnica, que, na sua perspectiva, a capacidade de pôr em prática uma liderança de tipo institucional supõe uma aprendizagem por parte dos professores. Não se nasce com essa capacidade, nem, por outro lado, essa capacidade é adquirida pela simples investidura num cargo institucional. Aliás, a ênfase que coloca na necessidade da aprendizagem de técnicas capazes de garantirem a efectiva aplicação dos pressupostos e características da liderança institucionalizada, baseiase no seu conhecimento dos problemas de controlo disciplinar enfrentados por muitos professores. Como recorda Waller (1932, p. 197), o "domínio e a subordinação nas escolas são usualmente discutidos nas escolas como 'disciplina'". Portanto, em termos puramente escolares, as técnicas de liderança institucional destinam-se a enfrentar esse problema. De um ponto de vista objectivo, a disciplina é, na definição proposta por Waller (1932, p. 197), "[...] um arranjo social, através do qual uma pessoa é capaz de exercer controlo sobre as acções dos outros"; de um ponto de vista subjectivo, "é a moral obtida sob a liderança institucional".

Com base nestes conceitos, Waller (1932, p. 198-207)) analisa as técnicas usadas pelos professores para manterem a disciplina, realçando que "podem ser classificadas, aproximadamente, no grau da sua utilização do institucional e do arbitrário, e inversamente, em relação à sua dependência da influência pessoal". As técnicas analisadas são as seguintes: comando, punição, manipulação das relações pessoais e de grupo, cólera e apelo. A técnica de "comando" é a que com maior eficácia protege a relação institucional de dominação -subordinação, o que se deve à sua extrema formalização e à completa erradicação de qualquer componente pessoal (ou seja, afectiva ou emocional) entre o líder (o professor) e os liderados (os alunos). Em última análise, a sua eficácia reside no facto de a formalização impedir o líder de ver a sua posição ameaçada por qualquer atitude que extravase o seu campo legal de autoridade institucio-

4 Waller (1932) descreve com detalhe cada uma das técnicas de liderança institucional. 
nal, circunstância que pode ser aproveitada pelos subordinados para enfraquecer a sua posição. Este perigo pode verificar-se nomeadamente na utilização das técnicas de punição, manipulação das relações pessoais e colectivas e na cólera, pois trata-se de técnicas em que frequentemente é difícil evitar a influência de factores pessoais. Por fim, a técnica do apelo ou súplica, escapa à tendência acima referida, pois destinase a lidar com situações consideradas de pouca gravidade.

De acordo com Waller (1932, p. 209), "estas não são de maneira nenhuma todas as técnicas usadas pelos professores na tentativa de manterem esta confusa relação a que chamamos disciplina. Provavelmente todos os professores usam todas estas técnicas e mais, mas com diferentes ênfases e em diferentes graus". Todas elas se destinam a proteger a posição de autoridade do professor, vista como condição sine qua non do processo educativo:

\begin{abstract}
A mais importante relação social do professor é a relação com os seus alunos; é esta relação que é o ensino. [...] A relação professor-aluno é uma forma especial de domínio e subordinação, uma relação muito instável e em equilibrio instável, não muito apoiada pelo braço forte da autoridade, mas dependendo largamente sobre a pura ascendência pessoal. [...] 0 conflito faz parte do papel, porque os desejos do professor e dos alunos são necessariamente divergentes e pode surgir mais conflito desta divergência de motivos porque o professor deve proteger-se da possivel destruição da sua autoridade (WALLER, 1932, p. 383).
\end{abstract}

Em sintese, destacamos como tópicos centrais para o debate actual sobre educação escolar em particular, a importância conferida por Waller a uma visão e estruturação hierárquica da relação educativa e pedagógica e a sua defesa da liderança institucional como elemento chave do controlo da interacção na sala de aula por parte dos professores.

\title{
Philip Jackson ${ }^{5}$
}

\section{A autoridade institucional dos professores e a resistência dos alunos}

Em Life in Classrooms, Jackson (1968) analisa a interacção na sala de aula com base no pressuposto, que partilha com Durkheim e Waller, de que essa interacção é potencialmente conflitual, devido à divergência de objectivos e interesses entre os professores e os alunos. Jackson (1968), começa por deixar claro que o sucesso na escola implica, necessariamente, esforço, luta por objectivos e sacrifício de interesses pessoais. É em relação a estas exigências institucionais que se levantam as resistências dos alunos, resistências essas em boa parte provocadas por factores relaci-

\footnotetext{
5 Philip W. Jackson, psicólogo e pedagogo americano, actualmente reformado, após ter trabalhado, desde 1955, nos Departamentos de Educação e Psicologia da Universidade de Chicago, produz no clássico Life in Classrooms, publicado em 1968, uma penetrante análise sociológica da interacção na sala de aula, apresentando uma visão muito próxima da de Waller.
} 
onados com o seu nível de desenvolvimento emocional e psicológico. É esta resistência natural dos alunos ao projecto social da escola, que obriga a que a acção educativa tenha de ser enquadrada num específico contexto institucional:

\begin{abstract}
[...] Segundo uma das muitas definições possíveis, o trabaIho implica envolver-se numa actividade orientada para um fim e ordenada por outra pessoa, uma actividade que não empreenderíamos se não existisse um sistema de relações hierárquicas. Antes de irem para a escola os alunos podem ter trabalhado a brincar, mas à imitação lúdica do trabalho dos adultos falta um ingrediente essencial: a submissão a um sistema heterónomo de autoridade que lhes ordene o que têm que fazer e os obrigue a fazê-lo. 0 professor, mediante as suas ordens e o seu controlo sobre os alunos, constitui o ingrediente necessário que faz que o trabalho seja real. 0 professor mesmo que possa resistir a este qualificativo, é o primeiro 'chefe' dos alunos (JACKSON, 1968, p. 47).
\end{abstract}

\title{
0 professor como superior hierárquico
}

$\mathrm{Na}$ visão de Jackson (1968), o professor deve desempenhar o papel do superior hierárquico que obriga os subordinados a trabalhar, exigindo esforço, aplicação e sacrifício. Jackson (1968, p. 20-21) enfatiza o carácter impositivo da experiência escolar através da comparação da escola com determinadas "instituições totais":

Há um facto da vida do alunos que os professores e os pais preferem silenciar, pelo menos diante dos alunos. É o facto de os jovens terem de estar na escola, quer o queiram, quer não o queiram. Neste aspecto os alunos têm algo em comum com os membros de outras duas instituições sociais que implicam uma frequência involuntária: as prisões e os hospitais psiquiátricos. A analogia é dramática, mas não a pretendemos levar ao extremo. Certamente não há termo de comparação entre a vida desagradável dos que se encontram retidos numa prisão ou num hospital psiquiátrico, por um lado, e as incomodidades quotidianas das crianças da escola primária, por outro lado. Sem embargo, a criança, em certo sentido, é um prisioneiro, como o adulto encarcerado. Também ele tem de enfrentar a inevitabilidade da sua experiência. Também ele tem que inventar estratégias para enfrentar o conflito que surge frequentemente entre a sua inclinação natural e as exigências da instituição.

Nesta situação social, o trabalho do professor legitimado pela autoridade institucional de que foi investido ${ }^{6}$, é justificado por referência à natureza da missão

6 Como explica Emerson (1962, p. 38): "A noção de legitimidade é importante, porque a autoridade é mais do que equilibrio de poder; ela é poder directo que pode ser empregue (legitimamente) apenas em canais definidos pelas normas do grupo. Uma pessoa que detenha tal autoridade é autorizada; ela não tem apenas o direito de mandar ou governar - ela é obrigada a isso. Por conseguinte, a autoridade emerge como uma transformação do poder chamada 'legitimação' [...] ". 
social da escola. Para Jackson, a escola não deve limitar-se à função técnica de transmissão de conhecimentos. Pelo contrário, é preciso ter em consideração que, como resultado social final, a educação visa a integração dos jovens na sociedade em que vivem. Ora, na sociedade, as relações sociais e institucionais estão organizadas de forma hierárquica, facto que, por si só, pode ser invocado, como aliás o faz Jackson (1968, p. 48), para evidenciar (e justificar) o carácter socialmente funcional da hierarquização da relação educativa:

No melhor dos mundos possíveis exige-se que as crianças se submetam à autoridade do professor que sejam 'trabalhadores' e 'alunos modelo'. Este ideal realiza-se em grande medida. Quase todos os alunos aprendem a fixar-se em algo e a prestar atenção quando Iho ordenam, a refrear as suas fantasias enquanto estão na aula. Esta disponibilidade para cumprir as ordens da autoridade docente é, por outro lado, duplamente importante porque o aluno terá que exercitá-la em muitos lugares extra-académicos. A passagem da classe à fábrica ou à oficina será mais fácil para aqueles que desde os seus primeiros anos tiverem desenvolvidos 'hábitos de trabalho'.

Dentro deste raciocínio, pode concluir-se que a realização dos objectivos da escola exige que o professor assuma o papel do líder institucional que apoiando-se na distância institucional e pessoal, na formalidade, e nas normas e regras institucionais, é capaz de impôr ao aluno as atitudes ajustadas à realização de um conjunto diversificado de tarefas escolares. Ou seja, o professor deve estar em condições de vencer a resistência activa ou passiva dos alunos, resistência essa que, na escola, é interpretada como indisciplina. Face à indisciplina, a escola aplica, como indica Jackson (1968, p. 35), "[...] sanções negativas - como a repreensão, o isolamento, a expulsão da aula". A penalização dos comportamentos considerados desviantes visa defender a autoridade do professor, enquanto requisito básico da aç̧ão educativa, algo que é válido mesmo para quem defenda abordagens pedagógicas alternativas. Com efeito, observa Jackson (1968, p. 35), mesmo nas escolas governadas segundo princípios anti-autoritários e anti-hierárquicos, uma análise rigorosa da relação social estabelecida na sala de aula torna evidente a manutenção da posição de superioridade institucional dos professores:

Pode ser que aos professores não Ihes satisfaça demasiado esta descrição e protestem insistindo que eles dirigem as suas turmas 'democraticamente', mas, em certo sentido, as suas responsabilidades são parecidas com as dos guardas de uma prisão. Nos cárceres 'progressistas', como em muitas escolas, se concede aos reclusos certas liberdades, sem que por isso se anulem as limitações existentes. Em ambas as instituições pode permitir-se que os subordinados prepa- 
rem uma festa no Natal, mas nunca se lhe permitirá que preparem a evasão. A dureza da desigualdade de poder entre professores e alunos pode agudizar-se ou atenuar-se de acordo com a política dos dirigentes e com as preferências de cada professor. Muitas das diferenças entre as instituiç̧ões classificadas de tradicionais e as chamadas progressistas provêm do modo de exercício da autoridade. Por exemplo, nalgumas escolas exige-se aos alunos que se ponham em pé quando o professor entra na turma, ao passo que em outras se lhes aconselha que tratem o professor por tu. Nalgumas se concede pouca participação aos alunos na elaboração do plano de estudos, enquanto que em outras se pede a sua colaboração, com o fim de dar mais conteúdo à experiência do aluno. Mas mesmo nos centros mais progressistas é o professor que tem o poder nas suas mãos e os alunos estão conscientes da autoridade e da posição chave do professor.

\section{A experiência e as perspectivas dos alunos}

Não obstante deixar claro que a sua visão da escola e da relação pedagógica implica necessariamente uma posição de domínio do professor, Jackson (1968), em Life in Classrooms, dá um significativo destaque ao relato e análise da experiência e das opiniões dos alunos sobre a escola. Vale a pena destacar este aspecto, pois, apesar de surpreendente, não é ainda hoje muito usual, mesmo no campo da sociologia da educação e da escola, ser considerada ou pesquisada a perspectiva dos alunos. Assim, para além de no primeiro capítulo, significativamente intitulado A Monotonia Quotidiana, descrever e analisar várias estratégias dos alunos (agradar ao professor, dissimular o incumprimento de tarefas ou regras, ganhar a benevolência do professor, evitar o confronto ou o conflito com o professor), Jackson dedica o segundo capítulo da obra intitulado Opiniões dos Alunos sobre a Escola, a apresentar e a analisar resultados de raras pesquisas (também no seu tempo) sobre as opiniões, as perspectivas e as atitudes dos alunos face à escola. Destaco aqui dois aspectos que considero de grande interesse para a análise sociológica da interacção na sala de aula. Em primeiro lugar, uma passagem sobre o tema das recordações da escola:

[...] os adultos que se deram ao trabalho de descrever as suas experiências da infância não ocultam que a aula era o paraíso para alguns, para outros era o inferno e um pouco de tudo para a maioria. Dois temas predominam nos escritos que descrevem os aspectos negativos da escola. 0 primeiro faz referência às experiências de medo ou de incomodidade provocadas pelas acções dos professores e companheiros cruéis e insensíveis. [...] o segundo tema faz referência ao aborrecimento originado pela imposição de tarefas absurdas, ou ao atractivo da vida fora dos muros da escola" (JACKSON, 1968, p. 58). 
E, em segundo lugar, uma observação de Jackson $(1968$, p. 131) que "diz tudo" sobre a centralidade que confere à liderança institucional, no contexto interactivo da sala de aula: "O professor que tenha 'perdido o controlo' da sua turma, não pode compensar esta deficiência nem fazendo uma avaliação muito boa, nem dedicando mais tempo ao grupo. De um ponto de vista pedagógico, quando se perde o controlo do grupo, tudo está perdido".

Em síntese, destacamos como tópicos centrais para o debate actual sobre educação e educação escolar em particular, a importância atribuída por Jackson às exigências institucionais da escola e à capacidade de resistência activa e passiva dos alunos.

\section{Conclusão}

A sociologia da interacção na sala de aula proposta por estes três autores clássicos deve, antes de mais, ser historicamente contextualizada, pois é preciso ter em consideração os quadros sociais e culturais e nacionais das épocas históricas a que se reportam as suas análises. Educação e Moral, o livro em que Durkheim mais desenvolveu a sua sociologia da sala de aula foi publicado em 1925, há, portanto, 83 anos; Sociology of Teaching, de Willard Waller, em 1932, há 76 anos; Life in Classrooms, de Philip Jackson, em 1968, há 40 anos. A relatividade 'antiguidade' destas obras pode levar a que sejam vistas como totalmente desactualizadas, sem terem, portanto, algo de relevante e útil a dizer ao público em geral, aos sociólogos da educação e aos professores em particular. Não penso que seja assim, por várias ordens de razões:

Uma primeira razão, terá que ver com a possibilidade de as concepções educacionais, ou, dito de outra forma, a ideologia educacional que enquadra estas análises sociológicas, ou seja, uma visão da educação como processo social que implica uma transmissão unilateral do património cultural, a imposição de valores e normas, a submissão a uma autoridade hierárquica e a um código disciplinar e que cultiva valores como 0 trabalho, o sacrificio de interesses pessoais, o esforço e o cumprimento dos deveres ser, ainda hoje, partilhada por muitos sectores políticos, sociais e educacionais. Diria, talvez de forma mais precisa, que esta visão unilateral, hierárquica, assimétrica e para muitos autoritária da educação poderá ser partilhada por todos aqueles que criticam os 'excessos' de liberdade, a hipervalorização dos direitos individuais, a deslegitimação da autoridade e das relações hierárquicas, que, de acordo com essa perspectiva, caracterizam, crescentemente, o panorama cultural de muitas das actuais sociedades democráticas, culturalmente abertas e política e ideologicamente pluralistas.

Uma segunda razão residirá na relevância e actual aplicabilidade da análise sociológica da relação pedagógica desenvolvida por estes autores, pois a sociologia do conflito - que inspira uma visão da interacção da sala de aula como 'campo de batalha' - continua a evidenciar uma forte capacidade explicativa de muitas situações e dinâmicas interactivas na escola e na sala de aula. Isso acontece porque a 
aplicação dos conceitos próprios desta sociologia - por exemplo, os conceitos de poder, de força, de estratégia, de táctica, de interesses em jogo, de dominação, de subordinação - continua a fazer sentido. Todavia, à luz da investigação mais "actual" - particularmente aquela desenvolvida ao longo das décadas de 1980 e 1990 do século XX - é preciso reconhecer os limites teóricos do modelo do conflito, que 0 impedem de dar conta de dinâmicas e configurações interactivas na sala de aula marcadas e impulsionadas pela reciprocidade ou até mesmo pela cooperação consensual, ou seja, por lógicas de acção convergente, nas quais a autoridade dos professores não é questionada ou ameaçada? .

Uma terceira razão tem que ver, justamente, com a importância decisiva que é atribuida por estes autores ao papel da autoridade na relação educativa e pedagógica. A autoridade, ou melhor dito, uma certa forma de autoridade, constitui um tópico essencial destas análises. Para Durkheim, Waller e Jackson, ela é um factor absolutamente central na acção educativa (na família, na escola, [...]). Mas, por exemplo, para quem tenda a ver em Durkheim um sociólogo radicalmente tradicional e conservador, é interessante chamar a atenção para a sua recusa do autoritarismo (com a sua distinção conceptual entre autoridade e autoritarismo), para a sua visão da educação como acção fundamentalmente explicativa e persuasiva (com a sua distinção entre educação e domesticação), para a sua recusa da militarização da sala de aula, e, muito especialmente, para a sua recusa da coacção física ou psicológica como meio ou técnica de controlo disciplinar (é preciso, defende Durkheim, respeitar integralmente a dignidade e a individualidade dos alunos). Em linguagem actual, diriamos pois que, nesta perspectiva, Durkheim lançou as bases para uma reconceptualização da autoridade na educação, como 'autoridade democrática', ou seja, um tipo de autoridade capaz de impor o respeito por valores, normas e deveres, mas no respeito pela integridade e direitos dos alunos;

Das perspectivas teóricas de Durkheim, Waller e Jackson, o que valerá a pena reter no contexto tão profundamente alterado das actuais sociedades democráticas e (pós) modernas, caracterizadas por um processo de personalização individualista, nas quais entraram em crise, aparentemente irremediável, as grandes narrativas (educacionais e pedagógicas, também), a socialização disciplinar e os modelos de transmissão cultural assentes numa relação unilateral, assimétrica e hierárquica entre as gerações adulta e jovem? ${ }^{8}$. Será que um modelo de escola hierárquico, um

\footnotetext{
7 Blackledge e Hunt (1985, p. 271), apoiam este ponto de vista, quando criticando a sobre-utilização do conceito de poder nas análises sociológicas da interacção na sala de aula, defendem a utilização selectiva dos conceitos de poder e de autoridade: [...] existem situações em que os alunos permitem, e na verdade esperam que o professor defina a situação para eles sem negociação. [...]. É assumido que os professores tentam impor a sua vontade aos alunos ou que estão dispostos a fazê-lo. Mas há um conceito associado ao de poder, o de autoridade, que Weber definiu como poder legítimo. Se uma pessoa aceita a autoridade da outra, ela permite que ela defina a situação, ou parte dela. Interessantemente encontramos poucas referências à autoridade nos estudos sobre a sala de aula, apesar de ser evidente que os professores estão conscientes da necessidade, por vezes, estabelecerem e manterem a sua autoridade. [...] 0 modelo do poder de indivíduos impondo deferentes definições e negociando certas formas de compromisso não é de modo nenhum o único modelo que poder ser aplicado nas escolas".

8 Gilles Lipovetsky $(1988$, p. 10):" Foi a anexação cada vez mais patente das esferas da vida social pelo processo de personalização e o recuo concomitante do processo disciplinar que nos levou a falar de sociedade pós-moderna".
} 
modelo pedagógico assimétrico e impositivo, terá alguma hipótese de resistir às profundas mudanças das relações de autoridade nas escolas (redução do alcance da autoridade escolar, ausência de consenso na definição dos direitos e deveres dos professores e dos alunos, perda de legitimidade dos modelos de autoridade quaseparentais e sua progressiva substituição por concepções de autoridade de tipo profissional, limitação das formas de punição disponiveis, mudança nas concepções de autoridade na sociedade, mudanças na concepção dos direitos e deveres apropriados das escolas e dos alunos, na sociedade em geral e entre os educadores e os próprios alunos) a que assistimos, desde a década de 1960, em muitas sociedades modernas, altamente industrializadas, urbanizadas e tecnologicamente evoluídas??. Não será chegada a hora de uma profunda revisão das bases hierárquicas, autoritárias, unilaterais, impositivas, e, em certa medida não democráticas, em que assenta o modelo tradicional de relação institucional, educativa e pedagógica com as jovens gerações, e de nos empenharmos na construção de um novo tipo de escola e de relação educativa e pedagógica? ${ }^{10}$. Face às tensões conflituais que marcam - por vezes com elevados niveis de disrupção, agressividade e violência - a acção educativa e a instrução na escola de hoje em dia, diria, a um título muito pessoal, que vale a pena olhar para o que nos dizem Durkheim, Waller e Jackson para vermos melhor aquilo que numa sociedade democrática, aberta e pluralista se deve rejeitar - 0 regresso a uma educação assente numa concepção autoritária de disciplina ${ }^{11}$ - e aquilo que vale a pena reter - a ideia de uma escola que realmente o seja: isto é, uma escola apoiada em valores, regras e objectivos mais consensualmente construidos e assumidos; uma escola que integre e operacionalize melhor, ou seja, de forma menos tensa e crispada, a relação com os seus alunos, e que esteja especialmente atenta aos problemas relacionais e educacionais específicos que são particularmente colocados pela adolescência ${ }^{12}$; uma escola que de facto invista na formação cívica e democrática dos seus alunos; uma escola que com firmeza, mas também com alguma flexibilidade e tolerância, saiba equilibrar a relação entre direitos e deveres dos alunos; uma escola onde, sem ambiguidades, se rejeitem as condutas disruptivas ou violentas que inviabilizam qualquer acção (relação) educativa; uma escola em que, finalmente, a autoridade profissional dos professores não seja posta em causa, e onde, também, não haja ambiguidades sobre a importância do respeito por um código de conduta que permita o desenvolvimento normal e produtivo do processo ensino/aprendizagem.

9 Sobre esta questão, ver Christopher Hurn (1985).

10 Cf. GOMES, 1987.

11 Na formulação proposta por Weber (1997, p. 81): "disciplina chamar-se-á a probabilidade de, numa multidão dada de homens, encontrar uma obediência pronta, automática e esquemática a uma ordem, em virtude de uma atitude adestrada. [...] o conceito de disciplina engloba o treino da obediência acrítica e sem resistência das massas".

12 Cf. COLEMAN, 1992. 


\section{Referências}

BLACKLEDGE, D.; HUNT, B. Sociological interpretations of education. London: Croom Helm, 1985.

COLEMAN, J. C. The nature of adolescence. In: COLEMAN, J. C.; WARRENADAMSON, C. Youth policy in the 1990s: the way forward. London: Routledge, 1992.

DURKHEIM, E. Educação e sociologia. São Paulo: Melhoramentos, 1972. . Educação moral. Porto: Rés, 1984.

EMERSON, R. M. Power-dependence relations. American Sociological Review, Washington, DC, v. 27, n. 1, p. 31-41, 1962.

GOMES, C. A. A escola segundo os alunos. Educação, Sociedade \&t Culturas, Porto, PT, n.7, p. 157-176, 1987.

HURN, C. Changes in authority relationships in schools: 1960-1980. Research in Sociology of Education and Socialization, Greenwinch, CT, v. 5, p. 31-57, 1985.

JACKSON, P. W. La vida en las aulas. Madrid: Ediciones Marova, 1968.

LIPOVETSKY, G. A era do vazio: ensaio sobre o individualismo contemporâneo. Lisboa: Relógio D'Água, 1988.

WALLER, W. The sociology of teaching. New York: John Wiley \&t Sons, 1932.

WEBER, M. Conceitos sociológicos fundamentais. Lisboa: Edições 70, 1997.

Recebido em: 09/09/2008

Aceito para publicação em: 24/06/2009 
